\title{
A case of low serum insulin levels in a patient with insulinoma
}

\author{
Chun-Han Lo' and Ding-Ping Sun ${ }^{2}$ \\ ${ }^{1}$ Chung Shan Medical University School of Medicine, Taichung, Taiwan and 2Department of Surgery, \\ Chi Mei Medical Center, Tainan, Taiwan
}

Correspondence should be addressed to Chun-Han Lo Email hawklo1211@gmail.com

\section{Summary}

Insulinomas are the most common cause of hypoglycemia resulting from endogenous hyperinsulinism. Traditionally, inappropriately elevated levels of insulin in the face of hypoglycemia are the key to diagnosis. However, contradictory levels of insulin and C-peptide do not necessarily exclude the diagnosis. A 50-year-old female was brought to our emergency department because of conscious disturbance on the previous night. She had no history of diabetes mellitus, and was not using any medications or alcohol. Laboratory data showed low sugar, a significantly low insulin level, and elevated C-peptide. After admission, she had multiple episodes of spontaneous hypoglycemia after overnight fasts without discomfort. It was considered that a neuroendocrine tumor was the source of her hypoglycemia. CT scan of the abdomen revealed a $1.1 \mathrm{~cm}$ hypervascular nodule in the pancreatic tail. Elective laparoscopic distal pancreatectomy was incorporated into her treatment course. A $1.2 \times 1.0 \mathrm{~cm}$ homogenous well-encapsulated tumor was resected. We monitored her glucose levels in the outpatient clinic every month for a period of six months. She did not have another episode of spontaneous hypoglycemia.

\section{Learning points:}

- Insulinoma causes endogenous hypoglycemia - it cannot be ruled out in patients presenting with hypoglycemia and low insulin levels; history and imaging studies should be done for further assessment

- A 24-h fast test has the same clinical significance as that of 72-h fast test

- C-peptide is a useful biochemical marker in addition to serum insulin, which can be used to diagnose insulinomas

- CT scan is used to measure the tumor size and localize the tumor. However, definitive diagnosis is only achieved through histopathologic evaluation of diseased tissue

\section{Background}

Insulinoma, by definition, is the tumor of the pancreas that produces excessive amounts of insulin. In very few cases, insulin levels are low despite clinical evaluation suggestive of pancreatic adenoma. In cases with low insulin concentration, accurate diagnosis requires other clinical indicators such as C-peptide, CT scan and endoscopic ultrasonography. The management of the tumor requires precise localization and surgical resection for a definite treatment. We hereby present a case of an asymptomatic female with insulinoma that presents with low serum insulin levels.

\section{Case presentation}

A 50-year-old female was brought to our emergency department because of conscious disturbance on the (c) 2016 The authors http://www.edmcasereports.com Published by Bioscientifica Ltd 
Chun-Han Lo and

Ding-Ping Sun
Low serum insulin levels in a
ID: 16-0041; August 2016 DOI: 10.1530/EDM-16-0041
Table 1 Initial biochemical investigations at ER.

\begin{tabular}{l}
\hline Parameter \\
\hline C-peptide $(\mathrm{ng} / \mathrm{mL})$ \\
Insulin $(\mu \mathrm{lU} / \mathrm{mL})$ \\
Glucose $(\mathrm{mg} / \mathrm{dL})$ \\
$\mathrm{Na}(\mathrm{mmol} / \mathrm{L})$ \\
$\mathrm{K}(\mathrm{mmol} / \mathrm{L})$ \\
Ammonia ( $\mu \mathrm{mol} / \mathrm{L})$ \\
Blood ketone body (mmol/L) \\
Cortisol $(\mu \mathrm{g} / \mathrm{dL})$ \\
TSH $(\mu / \mathrm{UL} / \mathrm{mL})$ \\
$\mathrm{T}_{3}(\mathrm{ng} / \mathrm{dL})$ \\
$\mathrm{T}_{4}(\mu \mathrm{g} / \mathrm{dL})$
\end{tabular}

\begin{tabular}{cccc}
\hline Value & & Reference range \\
\cline { 1 - 1 } 1.29 & & $1.77-4.68$ \\
$<1.0$ & & $2-17$ \\
41 & & $70-100$ \\
136.0 & & $136-145$ \\
4.11 & & $3.5-5.0$ \\
15 & & $11-32$ \\
0.4 & & $<0.6$ \\
20.7 & & $5-34$ \\
1.10 & & $0.25-4.0$ \\
61.31 & & $60-190$ \\
6.8 & & $4.5-12.5$ \\
& &
\end{tabular}

previous night. She did not complain of nausea, palpitations or diaphoresis. Her daughter denied alcohol consumption, use of illicit drug and any suicide attempt. Physical examination was insignificant. Her weight was $56 \mathrm{~kg}$ and had not changed recently. History revealed that she had had depression for over 3 years. She also experienced one episode of mild dizziness when standing after an overnight fast in the past, but it had resolved spontaneously and had been short-lived. The patient denied a history of diabetes mellitus and any use of medication.

\section{Investigation}

Laboratory workup revealed significantly low glucose $(41 \mathrm{mg} / \mathrm{dL})$, insulin $(<1.0 \mu \mathrm{IU} / \mathrm{mL})$ and C-peptide $(1.29 \mathrm{ng} / \mathrm{mL})$ levels. Serum levels of electrolyte, ammonia and ketone body are within normal limits (Table 1). CXR and EKG showed no significant finding. She was admitted for the evaluation of hypoglycemia. In the wards, she received a comprehensive check for hypoglycemia. Measurement of anti-insulin antibody (3.90\%), IGF1 (163.29 ng/mL) and IGF2 (421 ng/mL) levels was done in addition to that of glucose, c-peptide and insulin levels (Table 2). Abdominal CT scan showed a $1.1 \mathrm{~cm}$ hypervascular nodule in pancreatic tail, raising the suspicion of an islet cell tumor (Fig. 1). To rule out the possibility of multiple endocrine neoplasia type 1 (MEN1), she was screened for hormonal imbalance. Of all the hormone levels measured (FSH, LH, PTH, cortisol, prolactin, $\mathrm{T}_{3}, \mathrm{~T}_{4}$ and insulin), only

Table 2 Pre-operative laboratory data.

\begin{tabular}{lcc}
\hline Parameter & & Value \\
\cline { 1 - 1 } Glucose $(\mathrm{mg} / \mathrm{dL})$ & & 42 \\
C-peptide $(\mathrm{ng} / \mathrm{mL})$ & & 1.03 \\
Insulin $(\mu \mathrm{lU} / \mathrm{mL})$ & & 1.67 \\
Insulin antibody $(\%)$ & & 3.90 \\
HbA1c $(\%)$ & & 4.3 \\
\hline
\end{tabular}

\begin{tabular}{c}
\hline Reference range \\
\hline $70-100$ \\
$1.77-4.68$ \\
$2-17$ \\
N/A \\
$4-6$
\end{tabular}

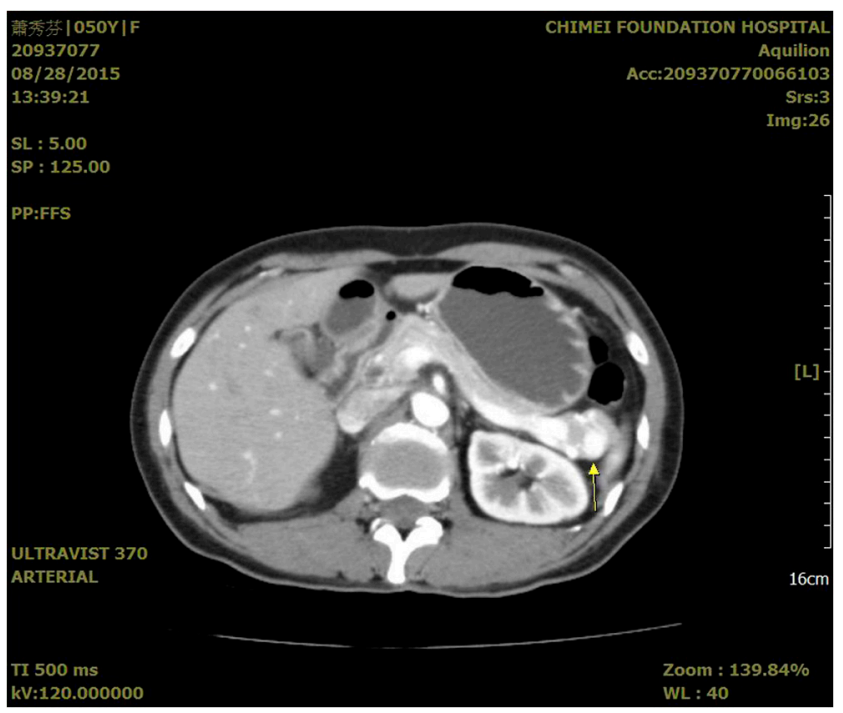

Figure 1

CT scan of abdomen revealed a hypodense solid lesion, without contrast enhancement, of about $1.0 \mathrm{~cm}$ in size at anterior aspect of pancreatic tail (marked with arrow).

prolactin levels appeared to be elevated $(47.2 \mathrm{ng} / \mathrm{mL})$, pointing out a possible prolactin-secreting adenoma in the pituitary gland, this was further confirmed by the presence of a $7 \mathrm{~mm}$ microadenoma in the left paramedian aspect of the pituitary gland. However, the patient did not show signs or symptoms related to prolactin over-secretion (headaches, vision problems that could be easily explained, menstrual cycle changes, mood swings and weight changes).

\section{Treatment}

We closely monitored her glucose levels and any potential hypoglycemic symptoms. Supportive treatment was implemented. Contrary to our belief of a pancreatic neuroendocrine tumor, her insulin and C-peptide levels were low - $1.67 \mu \mathrm{IU} / \mathrm{mL}$ and $1.03 \mathrm{ng} / \mathrm{mL}$ respectively. Although her blood glucose levels frequently dropped below $50 \mathrm{mg} / \mathrm{dL}$ after an overnight fast, she remained free of hypoglycemic symptom throughout the course. She was discharged after her condition stabilized.

The patient was asked to perform self-monitoring of blood glucose (SMBG) after she returned home. She was also encouraged to prevent hypoglycemia with high carbohydrate intake. SMBG data suggested a regular pattern of blood glucose levels. Her blood glucose was usually lowest in the morning, around $45 \mathrm{mg} / \mathrm{dL}$, and highest during the afternoon. MRI performed at the outpatient clinic was consistent with previous CT result, 


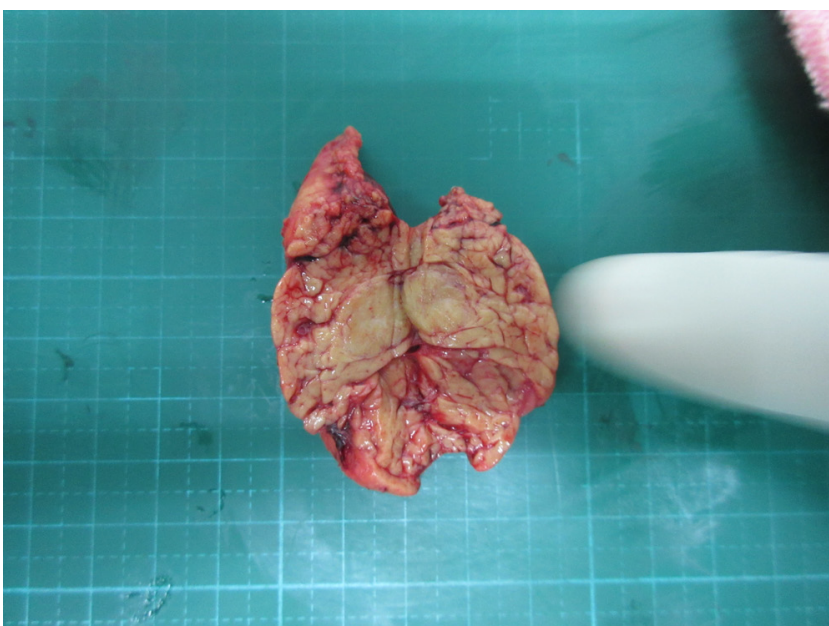

\section{Figure 2}

Surgical specimen revealed a homogenous, light yellowish in color, solid tumor with clear margin in the center of a piece of wedge-resected pancreatic tissue

most likely a pancreatic neuroendocrine tumor. Based on clinical, biochemical and imaging studies, the patient was referred to the surgical division. Due to her persistent hypoglycemic pattern, we arranged a laparoscopic distal pancreatectomy for resection of the tumor. Under general anesthesia, a $1.2 \times 1.0 \mathrm{~cm}$ homogenous well-encapsulated tumor was resected from the pancreatic tail without local complications or bleeding (Fig. 2). Pathologic examination revealed neuroendocrine tumor grade 1 (pT1) as the final diagnosis.

\section{Outcome and follow-up}

At 2-day follow-up, her blood glucose levels ranged from 84 to $146 \mathrm{mg} / \mathrm{dL}$, and no hypoglycemic episode was observed after an overnight fast (Table 3). We continued to monitor her glucose levels in the outpatient clinic every 1 month for a period of 6 months. She did not have another episode of spontaneous hypoglycemia.

Table 3 Post-operative glucose levels.

\begin{tabular}{lc}
\hline Post-operative day 1 & $\mathrm{mg} / \mathrm{dL}$ \\
$08: 00$ & 102 \\
12:00 & 129 \\
16:00 & 126 \\
22:00 & 116 \\
Post-Operative Day 2 & \\
08:00 & 94 \\
12:00 & 146 \\
16:00 $22: 00$ & 84 \\
\hline
\end{tabular}

\section{Discussion}

Insulinomas are characterized clinically by Whipple triad: episodic hypoglycemia, central nervous system (CNS) dysfunction, and dramatic reversal of CNS abnormalities with glucose administration (1). Our patient did not show any symptoms except for the first encounter where she had conscious disturbance. She remained asymptomatic throughout the treatment course, although glucose levels frequently dropped to around $40 \mathrm{mg} / \mathrm{dL}$.

Because symptomatic hypoglycemia often manifests as CNS dysfunction, patients with hypoglycemia have often been misdiagnosed with neurological or psychiatric disorders (2). Our patient had a long history of psychiatric disorder, which can sometimes present with neurologic disturbances. The fact that the patient was not taking any antidepressant and that she had not had an episode for over a year suggested that her mental condition was relatively stable. She regained consciousness after administration of oral carbohydrate, therefore hypoglycemia seems to be the correct diagnosis. However, it is pivotal to identify all the underlying diseases while analyzing the reason for conscious disturbance.

For 75 years, the 72-h fasting test has been considered the 'gold standard' for the diagnosis of insulinoma. However, some studies questioned the necessity to extend the fasting to $72 \mathrm{~h}$. In 170 patients operated on for insulinoma who underwent prolonged fasts according to a standard protocol at the Mayo Clinic, the fast was terminated within $12 \mathrm{~h}$ in $33 \%, 24 \mathrm{~h}$ in $65 \%, 36 \mathrm{~h}$ in $84 \%, 48 \mathrm{~h}$ in $93 \%$ and $72 \mathrm{~h}$ in 99\% (3). Hirshberg et al. also conducted a similar study to assess the need for a 72-h fast for the diagnosis of insulinoma and concluded that 48 -h fast should replace the 72 -h fast as the new diagnostic standard in textbooks and hospital protocols (4). We did not conduct a formal 72-h fast test because our patient had spontaneous hypoglycemia as low as $40 \mathrm{mg} / \mathrm{dL}$ after a 12 -h overnight fast almost every morning. Her glucose level returned to the normal value upon having breakfast. A drop in glucose level to below $30 \mathrm{mg} / \mathrm{dL}$ as well as the appearance of neurologic symptoms could be anticipated if we extended the fast to $24 \mathrm{~h}$, but we considered it wise and humane to avoid inconvenience and hardship to the patient. An accurate diagnosis is required because of implications for radiologic studies and potential surgical intervention. The diagnostic accuracy of the prolonged fast for insulinoma in a series by Van Bon et al. was reported to be high, with sensitivity and specificity of 89 and $100 \%$, respectively (5).

In most cases, the diagnosis for insulinoma is usually a combination of satisfying the criteria of Whipple's triad, laboratory tests, imaging studies and, to a lesser 
extent, histologic findings (6). However, diagnosis can be difficult at times. Failure of endogenous insulin secretion to be suppressed by hypoglycemia is the hallmark of an insulinoma (7). Yet our patient repeatedly presents with abnormally low insulin and moderate C-peptide levels, making it difficult to identify the disease before we ordered abdominal CT scan. The Endocrine Society Clinical Practice Guidelines (ESCPG) were used to diagnose insulinoma. The ESCPG define endogenous hyperinsulinemic hypoglycemia as having a plasma glucose level of $<3.0 \mathrm{mmol} / \mathrm{L}$ ( $55 \mathrm{mg} / \mathrm{dL}$ ), an insulin level of $\geq 18 \mathrm{pmol} / \mathrm{L}(3.0 \mu \mathrm{U} / \mathrm{mL})$, a C-peptide level of $\geq 0.2 \mathrm{nmol} / \mathrm{L}(0.6 \mathrm{ng} / \mathrm{mL})$, and/or a proinsulin level of $\geq 5.0 \mathrm{pmol} / \mathrm{L}$ (8). This definition was not clear regarding how many of these criteria should be met to confirm the diagnosis of insulinoma. A comprehensive study discussing the clinical implication of this criteria reported that by meeting two of the criteria, mainly plasma glucose level of $<3.0 \mathrm{mmol} / \mathrm{L}$ $(55 \mathrm{mg} / \mathrm{dL})$ and C-peptide level of $\geq 0.2 \mathrm{nmol} / \mathrm{L}(0.6 \mathrm{ng} / \mathrm{mL})$, two of the four criteria that our patient met, the sensitivity and specificity could be 100 and $83 \%$, respectively. However, the sensitivity and specificity could be 100 and $89 \%$ if all three criteria were met (9). Hypoglycemia with low insulin and C-peptide levels often points to the consideration of non-islet cell tumor hypoglycemia (NICTH). In NICTH patients, the serum levels of insulin, C-peptide and IGF1 are usually decreased or undetectable. The serum IGF2 levels may be elevated, decreased or normal. Low serum insulin in combination with elevated levels of 'big'-IGF2 (partially processed forms of pro-IGF2) and an increased IGF2:IGF1 ratio would confirm the diagnosis (10). However, given that our patient's IGF1 $(163.29 \mathrm{ng} / \mathrm{mL})$ and IGF2 $(421 \mathrm{ng} / \mathrm{mL})$ levels were normal and the IGF2:IGF1 ratio was not increased, NICTH is not likely to be the diagnosis. Another type of endogenous hypoglycemia - autoimmune form of hypoglycemia - should also be considered. However, patients with autoimmune hypoglycemia tend to have high levels of anti-insulin and/or insulin receptor antibodies. This possibility could also be ruled out due to low levels of antiinsulin antibodies (3.90\%) in the patient's body.

Despite all the deductions from biochemical criteria, imaging studies are still required for accurate identification of the tumor's size and location. In conclusion, our insulinoma patient who presented with low serum insulin levels informed us that if the supposedly high insulin levels failed to rise, C-peptide levels along with imaging studies could be the alternative indicators that this patient suffers from insulinoma.
Declaration of interest

The authors declare that there is no conflict of interest that could be perceived as prejudicing the impartiality of the research reported.

\section{Funding}

This research did not receive any specific grant from any funding agency in the public, commercial or not-for-profit sector.

\section{Patient consent}

Written and oral informed consent was obtained from the patient for publication.

\section{Author contribution statement}

Chun-Han Lo drafted the manuscript, collected all the required data and images for the case, and came up with the discussion points of the case. Ding-Ping Sun revised the manuscript.

\section{References}

1 Kong M-F, Lawden M \& Dennison A 2010 Altered mental state and the Whipple triad. BMJ Case Reports 2010 bcr0820092158. (doi:10.1136/bcr.08.2009.2158)

2 Dizon AM, Kowalyk S \& Hoogwerf BJ 1999 Neuroglycopenic and other symptoms in patients with insulinomas. American Journal of Medicine 106 307-310. (doi:10.1016/S0002-9343(99)00021-2)

3 Service FJ \& Natt N 2000 The prolonged fast. Journal of Clinical Endocrinology and Metabolism 85 3973-3974. (doi:10.1210/ jcem.85.11.6934)

4 Hirshberg B, Livi A, Bartlett DL, Libutti SK, Alexander HR, Doppman JL, Skarulis MC \& Gorden P 2000 Forty-eight-hour fast: the diagnostic test for insulinoma. Journal of Clinical Endocrinology and Metabolism 85 3222-3226. (doi:10.1210/jcem.85.9.6807)

5 Van Bon AC, Benhadi N, Endert E \& Fliers E 2009 Evaluation of endocrine tests. D: the prolonged fasting test for insulinoma. Netherlands Journal of Medicine 67 274-278.

6 Okabayashi T, Shima Y, Sumiyoshi T, Kozuki A, Ito S, Ogawa Y \& Hanazaki K 2013 Diagnosis and management of insulinoma. World Journal of Gastroenterology 19 829-837. (doi:10.3748/wjg.v19.i6.829)

7 Shin JJ, Phillip G \& Libutti SK 2010 Insulinoma: pathophysiology, localization and management. Future Oncology 6 229-237. (doi:10.2217/fon.09.165)

8 Cryer PE, Axelrod L, Grossman AB, Heller SR, Montori VM, Seaquist ER \& Service FJ 2009 Endocrine Society. Evaluation and management of adult hypoglycemic disorders: an Endocrine Society clinical practice guideline. Journal of Clinical Endocrinology and Metabolism 94 709-728. (doi:10.1210/jc.2008-1410)

9 Ahn CH, Kim L-K, Lee JE, Jung CH, Min SH, Park KS, Kim SY \& Cho YM 2014 Clinical implications of various criteria for the biochemical diagnosis of insulinoma. Endocrinology and Metabolism 29 498-504. (doi:10.3803/EnM.2014.29.4.498)

10 de Groot JW, Rikhof B, van Doorn J, Bilo HJ, Alleman MA, Honkoop AH \& van der Graaf WT 2007 Non-islet cell tumourinduced hypoglycemia: a review of the literature including two new cases. Endocrine-Related Cancer 14 979-993. (doi:10.1677/ERC07-0161)

Received in final form 15 July 2016

Accepted 27 July 2016 